\title{
SHADING EFFECT OF A SOUTH BUILDING ON THE SOLAR COLLECTOR APERTURE
}

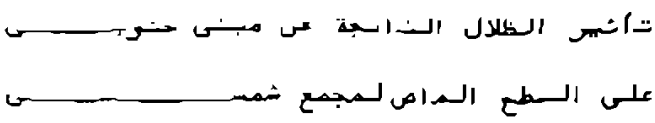

H. E. Gad

Mechanizal Fower Department, Faculty of Engineering Mansrura University, EGYFT.

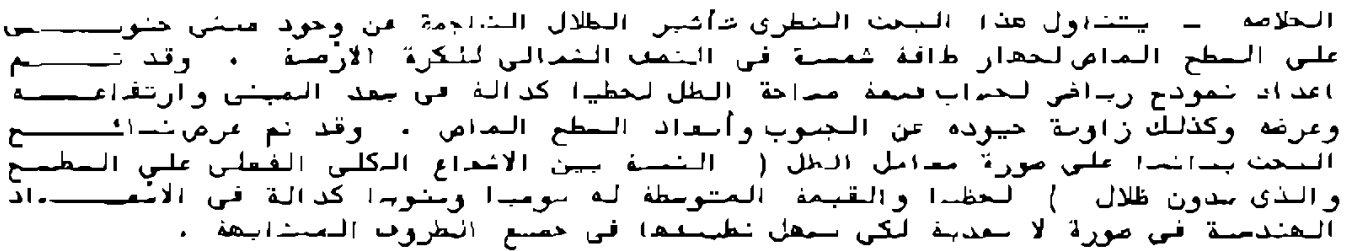

ABSTRACT - In the present work, the shading eflect of a south building on the aperture of a solar device in the north 1 atitudes is therretically investigatec. A mathematical model to calsulate the instantaneuus value uf sladed area as a function of building horizontal distance, neight, width and the angle of deviation from south direition as uell as aperture dimensions has been obtained. The shading lactor, which is the ratio between the actual total incident solar radiation and that without shading en the aperture, has been calculeted for different geometrical parameters. The annuai average shading factor, whish may be considered as a reasonable measure of the shading effect is alsa given in terms of the system dimensionless parameters.

\section{NTRODUCTI ON}

In large lities, buildings are usually erouded, making shadows on eacin ather and may produce a shading effert on the aperture of an existing solar devine. This ract is ane of the mest important reasons why the majority of city residents do not prefer the salar eheice. On the ather hand, the reperted wark in this riela is very little campared to the problem $51 z e$, and is not sufficient in practice. For example, an analytical method fer calculating daly and monthly average insalation on ovorhanging shaded windows af arbitrary azimuth is presented by Jones [1]. An extension sf this work for a finite width overhang has been reportad [2]. The preblem of window ghaders hag also been handled 
by Barozzi and Grossa [3], using the numerlcal technique.

On the other hand, the shading effects of large scale solar systems are studled by Jones and gurkhart [4]. An analytical method for calculating the daily total radiation on rovs of $f(x e d$ collectors facing equator has been reported. The effect of rou length is neglected, since it is pronounced only close to sunrise and sunset as reported. Similar vork on solar cell array has been pertormed by feldman et al (5). They proposed a non-regular distribution of cells to reduce the shadow effects. Mathematical models for shading calculations, suitable for computer - aided design of complex systems are also avallable [6].

Hovever, the shading probler of buildings on solar devices seems to be very significant, especialiy in cities and touns. This vork is therefore aimed to investigate the effect of a south building shading on a solar device, since the style of buildings ls mostly east - vest, in north latitudes. A simple model and practical graphical resules are also presented.

\section{THEORETICAL APPROACH}

An aperture of a solar device of vidth $H$, and height $L$ is fixed in a place where the latltude is $\phi$, vith an angle of inciination $\beta$, to the horlzontal and facling south. In front of the aperture, there exists a nearby building at a horizontal distance trom the aperture botton edge of $z$ times the aperture height $($ i.e. $=z \mathrm{z}$ ). The bullding height is equal to $v L$, while Its vidth is $d H$, and is assumed to have an east-vest direction. The deviation of building from the south direction is measured by the angle $c$, betveen the line connectlng the mid points of the bottom aperture edge and the building width, and the south directioir in a horlzontal plane. The system geometry is shovn in Fig. I. In the elevation viev, the signiflcant parameters wich explain the geometrical relations between the bean solar radiation, aperture and the bullding are the extreme values of the profile angles $\lambda_{0}$ and $\lambda_{1}$, where,

$\tan \lambda=\frac{\tan \alpha}{\cos (\phi-\gamma)}$,

where $\alpha$, is the solar altitude angle and $\gamma$, is the aperture azimuth angle which is equal to zero ( aperture facing south). In the plan viev, the system geometry is characterized by the angle $c$, and extreme values of the solar azimuth angle a and $a_{p}$.

The shaded area for a certaln aperture-building geometrical 
Mansouxa Engíneexing Jouxnal(MEJ) Vol.14, No.1, Jure 1989 M 94

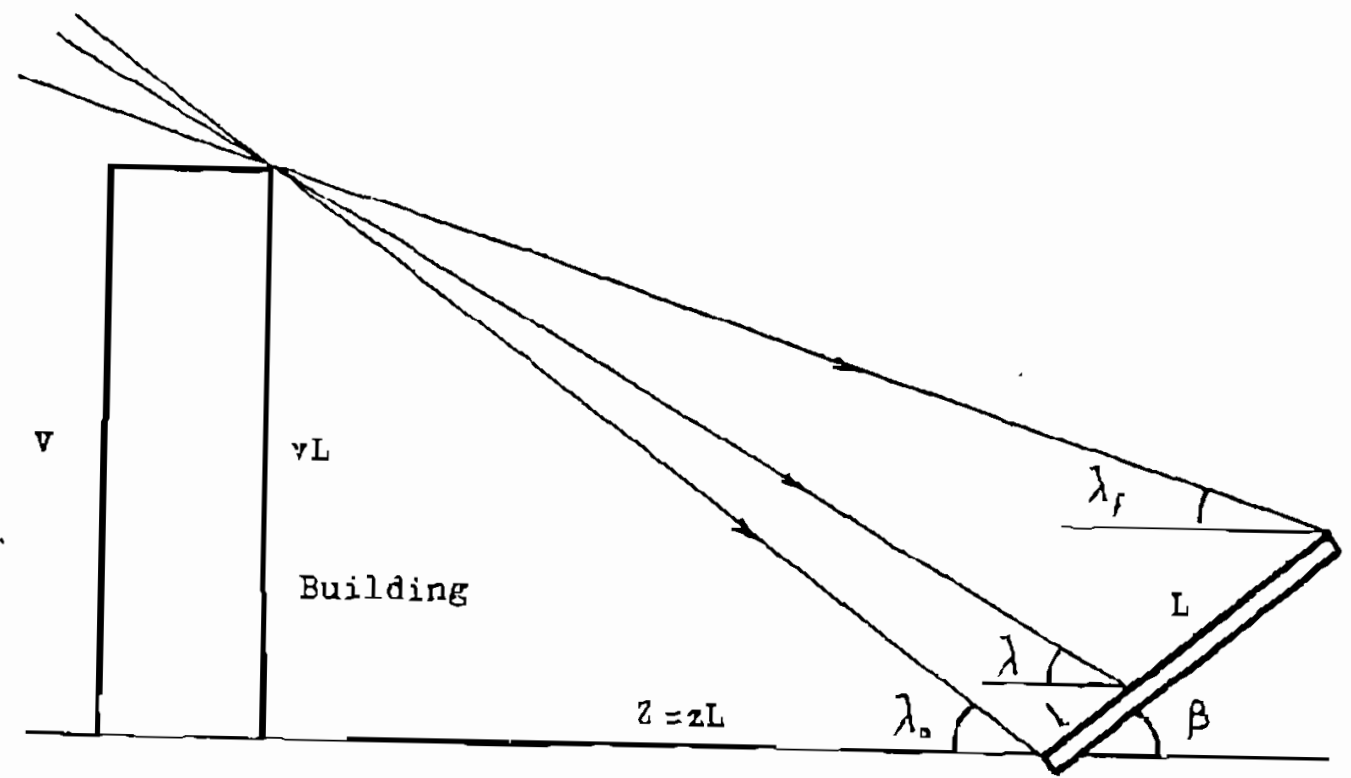

Elevation

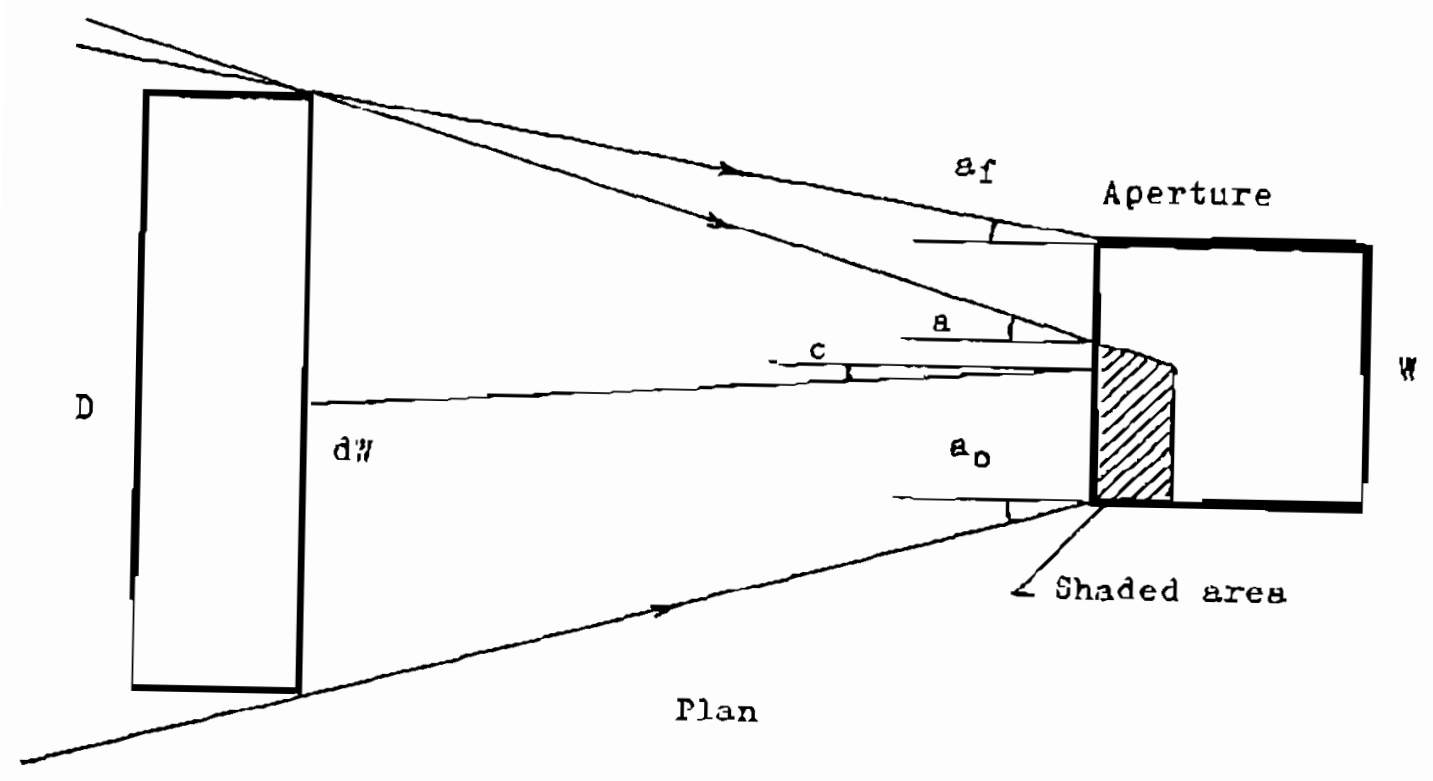

Fig. 1. Bullding - aperture system geometry. 
configuration is dependent only on the angles $\lambda$, and $a$, as shown In the figure. The aperture is Euliy 11 luminated if $\lambda \geq \lambda_{0}$, while lt Is completely ghaded if $\lambda \leq \lambda_{r}$ ( and $a \leq a$, ). The apecture is partly shaded if $\lambda_{0} \geq \lambda \geq \lambda_{f}$, and $a_{0} \geq a \geq a_{1}$, where

$\tan \lambda_{0}=v / 2$ and $\tan \lambda_{r}=\frac{v-\sin \beta}{2+\cos \beta}$

It can be shown from the front viev geometry that the profile angle 2 , is related to $z, v$ and $\beta$, at any time by

$$
\tan \lambda=\frac{v-(1 / 2) \sin \beta}{z+(1 / L) \cos \beta},
$$

where 1 , is the shade length in the aperture height direction. Eguations 1,2 and 3 could be used to. obtain the value of $(1 / \mathrm{L})$, in terms of the angle $\lambda$, as

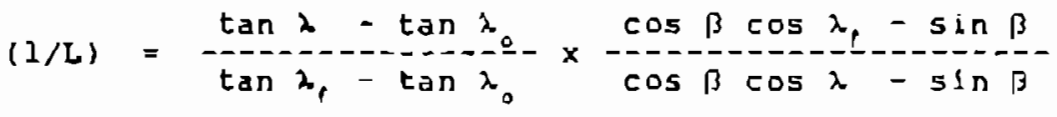

This equation is valid only when $\lambda_{0} \geq 2 \geq \lambda_{,}$. The value of (1/L) is equal to zero when $\lambda \geq \lambda_{0}$, and is unity if $\lambda \leq \lambda_{1}$.

From the plan system geometry, the following relationg can be easily derived,

$\tan a_{0}=\frac{d-1}{2 e^{2}}+\tan c ;$

$\tan a_{r}=\frac{d-\frac{1}{2}-\tan c ;}{2}-$

where $e=L / W$

The shade length at the aperture lover edge in the vidth direction $\forall$, is given by,

$(w / H)=1+e z\left(\tan a_{0}-\tan a\right)$ IE $a a_{0}$;

and $(v / H)=e d-e z\left(\tan a_{0}+\tan a\right)$, if $a \leq a$,

Equation 7 is valid only a.m., while the other is valid only p.m. The value of $(w / H)=1$ if $a_{0}, a, a_{\text {, }}$ and zero otherwise. The ratio $A_{r}$, of the shaded area to that of the aperture can be approximated by,

$$
R_{r}=(1 / L)(W / H)
$$


The "ASHRAE" Handbook of Fundamentals [7] recommends the folloving equation for the prediction of the normal beam solar radiation $\mathrm{H}_{\mathrm{b}}$,

$H_{b n}=H_{0} \exp (-B / \sin \alpha)$,

where $B$, is the atmospheric extinction coefficient.

The values of $H_{0}$ and $B$ are representative of condltions on average cloudless days for north latitudes (From 0 to 64 degrees) The "ASHRAE" Handbook of fundamentals also gives a simplified general relation for the diffuse solar radiation $\mathrm{H}_{d a}$ from a clear sky that falls on any terrestrial surface as,

$H_{d a}=0.5 E H_{b n}(1+\cos \beta)$,

where $E$, is the diffuse radiation factor which is given numerically for each month in the Handbook.

The average insolation on the aperture surface is given by,

$H_{a}=H_{b n}\left(1-A_{r}\right) \cos \theta+0.5 E H_{b n}(1+\cos \beta)$,

where $\theta$, is the incident angle of beam radiation on the aperture. The shading effect of the beam radiation is taken into account in the above equation, where the value of $A_{p}=0$ to 1 . Hovever, $a$ shading factor $\zeta$, may be defined by the ratio betueen the actual insolation on the aperture surface and that uithout shading,

$\zeta=\frac{(1-A+1 \cos \theta+0.5 E(1+\cos \beta)}{\cos \theta+0.5 f(1+\cos \beta)}$

According to this equation, the shading factor is only a function of time for any given aperture-building configuration. A computer program is systematically constructed to calculate $\zeta$, uith a time step of 0.25 hour, durlng every day over a year for different values of system geometrical parameters as shovn in Fig. 2 .

RESILTS AND DI SCUSSI OH:

Because the problem involves a large number of parameters, it ls necessary to keep some of them constant and investigate the influence of the others. On the other hand, the instantaneous values of shading factor during any day shov only its behavlor in the same day, but the daily average value is expected to be more useful in calculating the energy gain. Hovever, in order to investigate the influence of system different parameters, the annul average value of the shading factor is essentially 


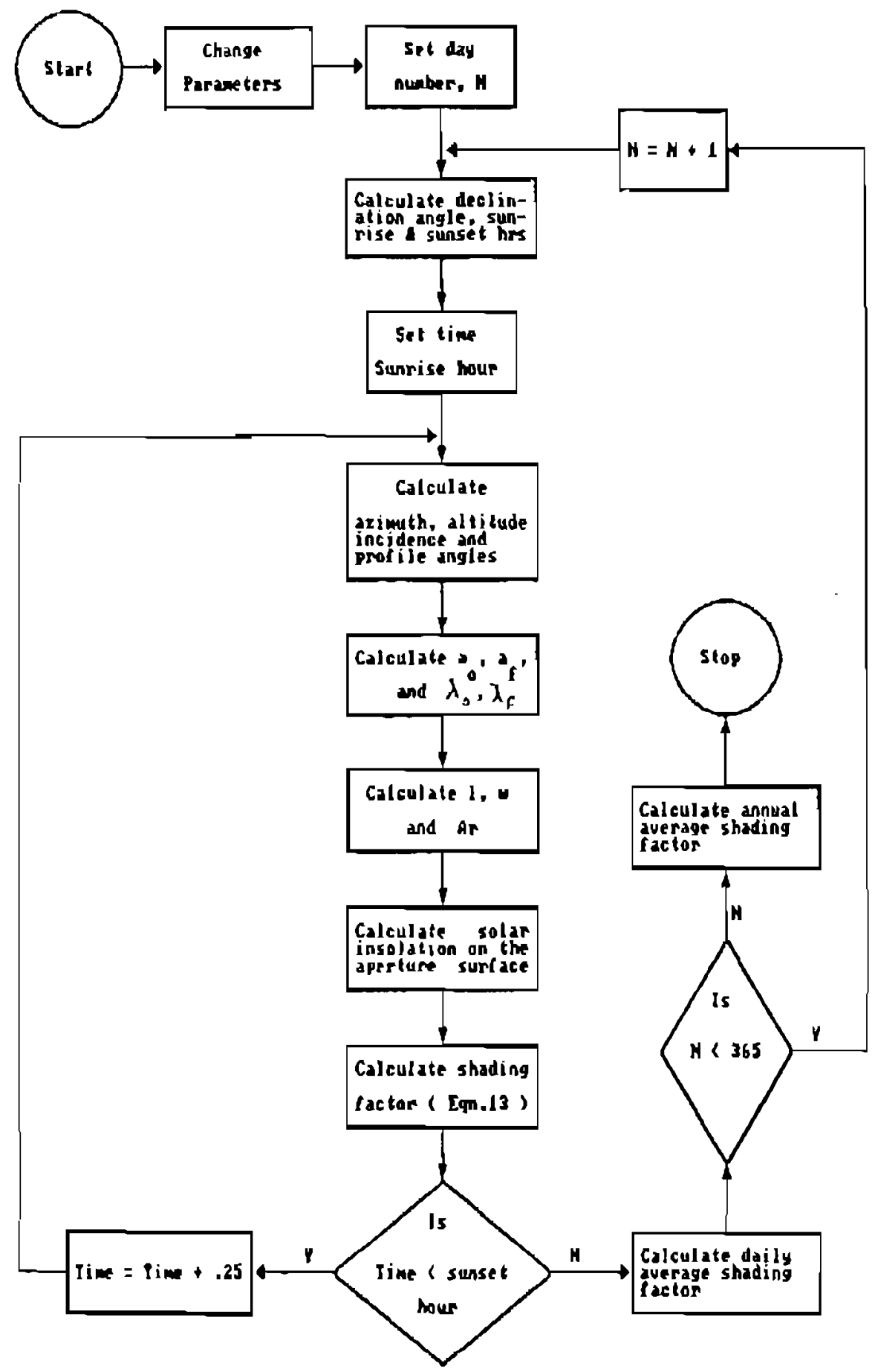

Fig. 2. Its flou diegran of the computer progran 
reguired. Results of this analysis, whjch are given In graphical Eorm, show the hourly values of shading factor in some days, daily and the annul average values under different parameters.

Eigure 3. Shows the hourly values of the shading factor resulting from a very long horizontal object at a distance $L$, from the aperture lower edge $(z=1)$. Thls object may be a building or an east-west wall in front of the aperture. The shading factor is plotted for different building heights during a summer day ( $N=172$ ). For all values of $v / z$, the shading factor decreases with time, from unity, reaching a minimum value at noon and then increases again to unity. It ls clear also that shading factor decreases wich increaslng helght. It is to be noted that the flat minimum in the case of $v / z=20$, is only due to diffuse radiation where the aperture is completely shaded during this period. Figures 4 and 5 . show similar results for a winter and a spring days respectively. In winter, the shading Eactor has a maximum value at noon for small bullding helghts as seen in Flg. A. However, in eguinoxes, it is almost independent of time as shown in Fig. 5, where $N=\theta 0$.

An example of of the effect of building width on the hourly values of the shading factor is giver in Fig. 6. This figure gives results for the day $N=172$, where the specific values of $z$, $v$ and c axe 1,13 and 0 respectively. As expected, the period during uhich shading factor is less than unity, increases $v i t h$ the building width. Also, all curves representing different values of $d$, are symmetrical around the noon line. However, figures from 3 to 6 are given under specially decided parameters to show reasonable variations of shading factor to demonstrate its daily behavior. otherwise, the shading factor is either unity or at its minimum corresponding to the diffuse radiation.

On the other hand, the daily average value of the shading factor for any system can be very useful in estimating the output energy distribution over the year to compare with the energy demand. In large cities, the apparent picture of building shading may be not encouraglng, but the actual energy distribution may fit the demand. Calculations can also be used for an already exlsting solar device. Figure 7 . is an example of daily average shading factor for a system with $z=10, d=20$ and $c=0$, at different values of $v / z$, over the year. As seen from the figure, the shadlng factor is at its ininimum value during winter months if $v / z=1$, then it increases rapidly to unity in othez days. For values of $v / z>1$, shading factor increases gradually from its mlnimum and then rapldiy. However, the shading factor is unlty ald over the year IE $v / z \leq \tan ^{-1}(1.16-\phi)$, for all values of $c$ and $d$. 


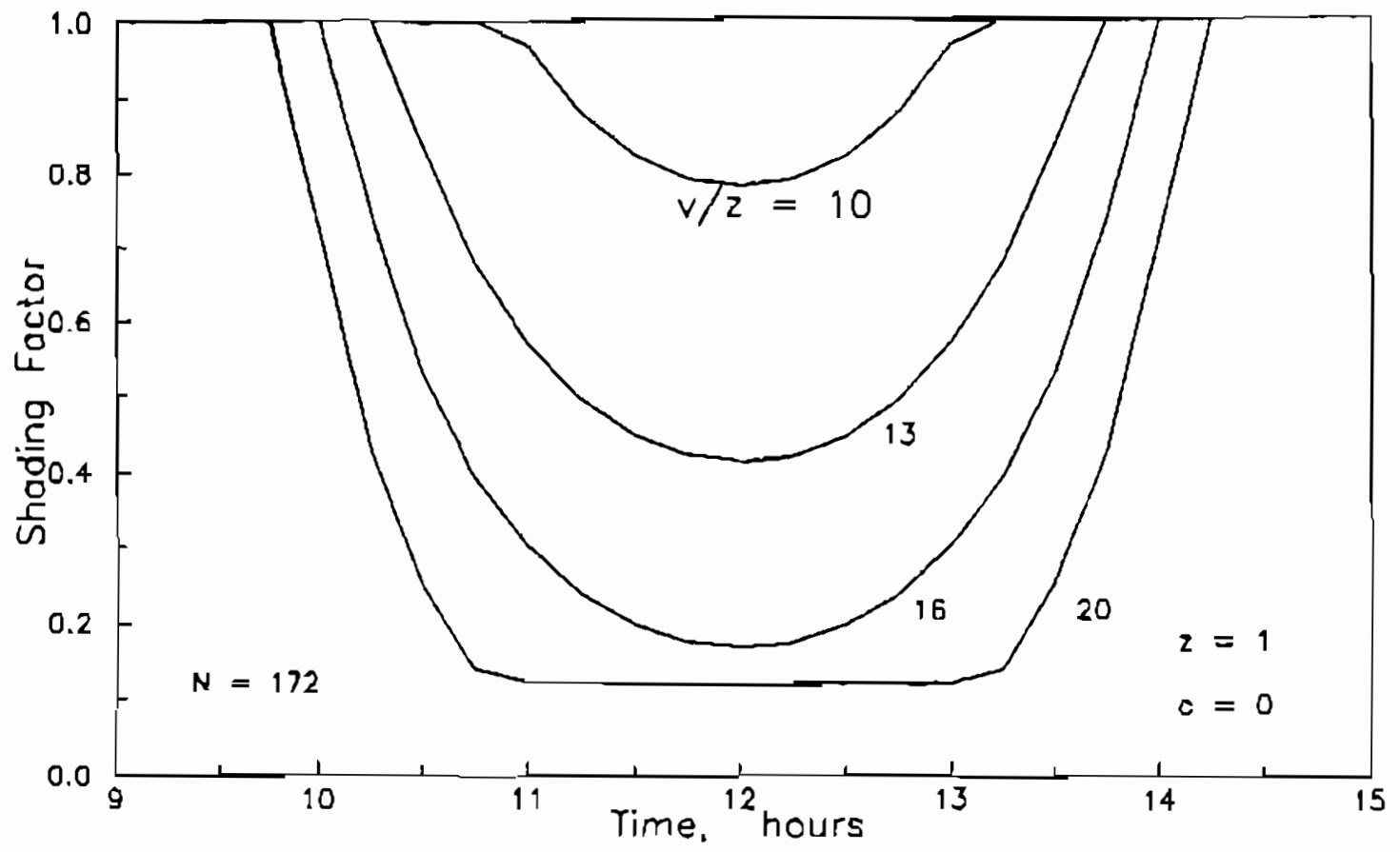

Fig. 3. Hourly variation of shading foctor for a summer day.

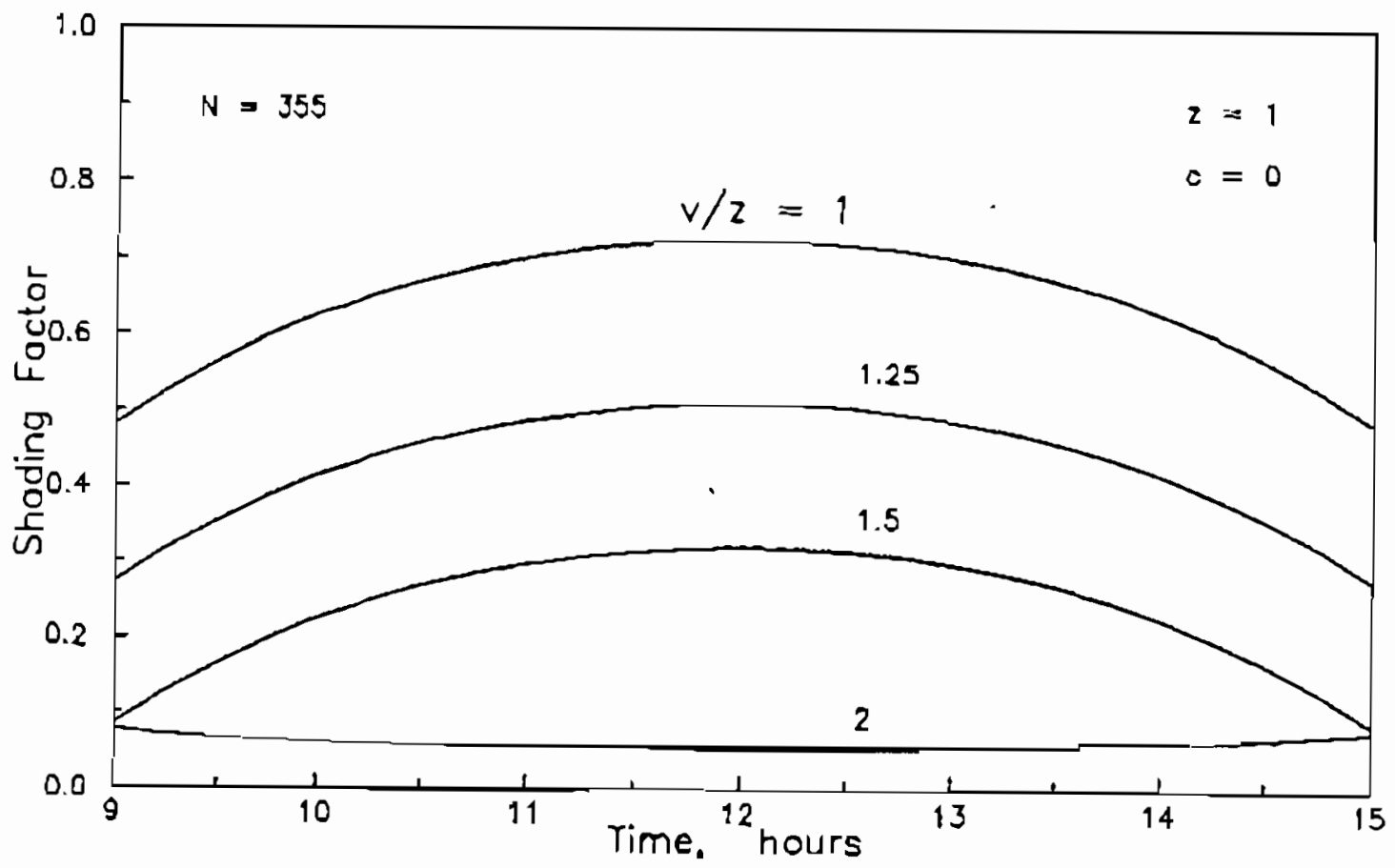

Fig. 4. Hourly voriation of shading foctor for a winter day. 
Mansoura Erginepring Journal(kE,) Vol.14, No.1, June 1989 M 100

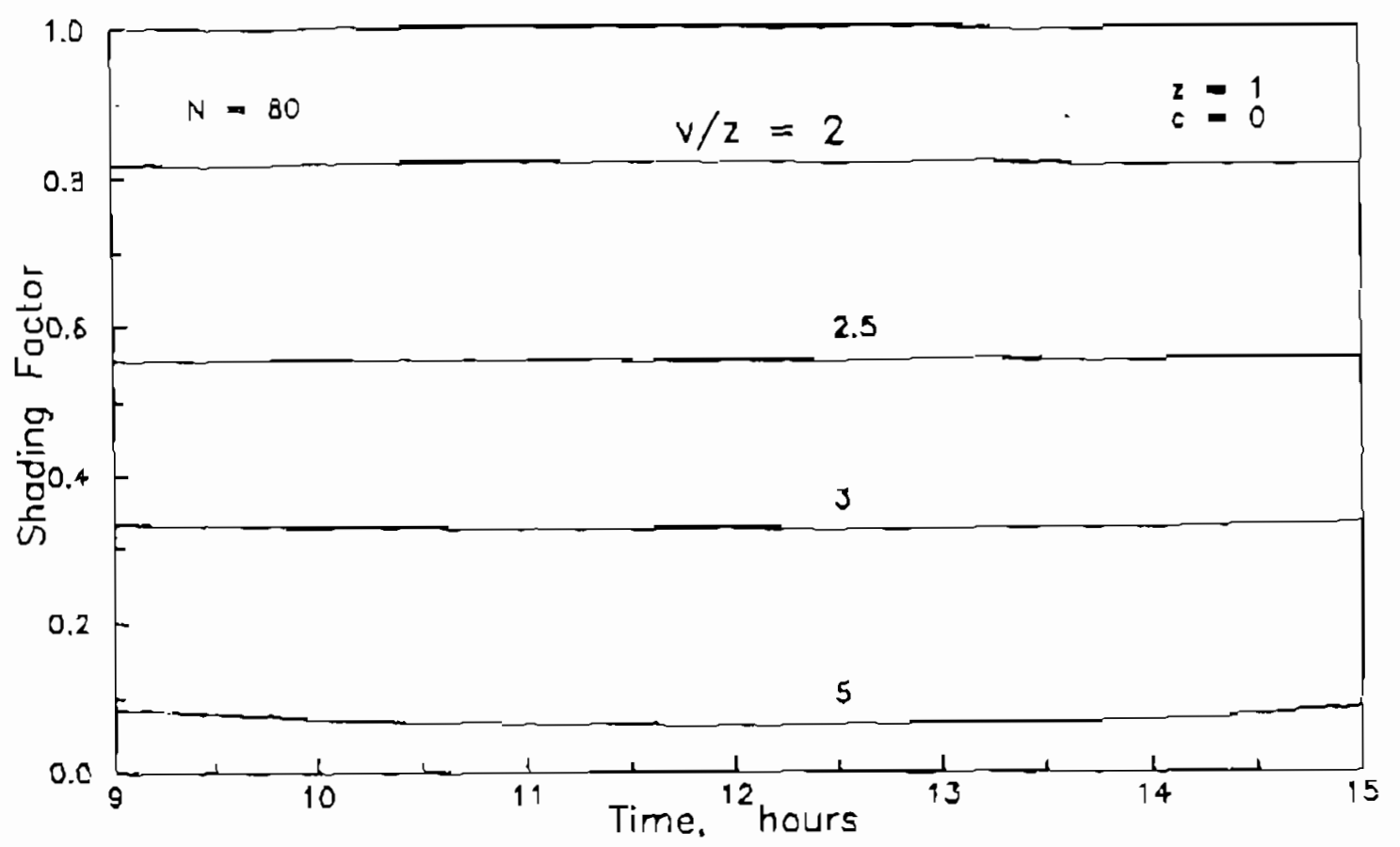

Fig. 5. Houriy varlation of shading factor for a spring day.

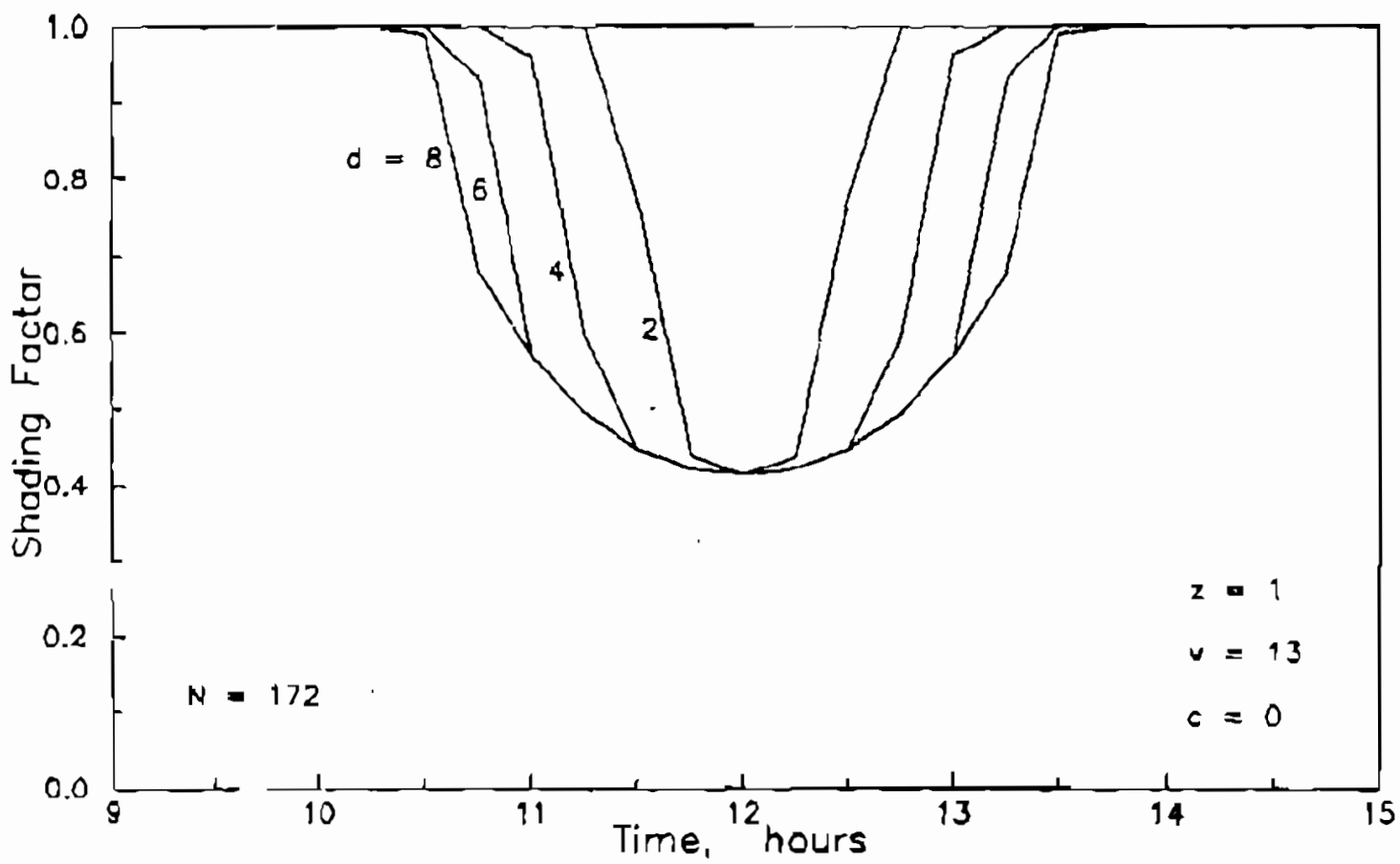

Fig. 6. Hourly variation of shading foctor in a summer day at different values of builcing widths. 
The effect of building vidth on the shading factor for the case of $v / 2=2$, is shovn in Fig. $\theta$. It is clear that the number of days vith unity shading factor is not affected by the buiding vidth. Only the change from infrimum is seen to be more gradual, and the value of minimum shading factor increases vith smalier building widths. The shading factor is of course unity when $d=0$.

However, the average value of shading factor over a year is more practical for design purposes. Figure 9 . shows the annual shading factor as a function of 2 , at different values of $v / z$, for $d=10$ and $c=0$. Since $z, v$ and $d$ are dimensionless parameters, this graphical representation can be used to determine shading Eactor for any system geometry having the same values of d and $c$. As an example, the annual shading factor resulting from a building vith height to horizontal distance of unity, and at a distance of 5 times the operture height is about 0.8 . In this case, a layman may think that this site is not suitable for any solar system.

Figure 10. shows the same results at different values of building widths ( $a=5,20$ and 40 ), for a vide range of horizontal distances( $z \leq 20$ ). The shading factor decreases with the increase in building width for all values of $v / 2$. This effect increases with the horizontal distance. Also, it can be seen from the figure that the shading factor decreases with $z$, to a minimum value and then increases again and tends to have a constant value at larger $z$, for any $v / z$. The value of $z$, at which this minimum occurs increases with the boilding width. Finally, the effect of angle $c$, on the shading factor for the system geometry with $d=z_{\text {, }}$ (i.e. the building wiath is equal to the horizontal distance) is shown in Fig. 11. The angle $c$, is seen to have a marked effect on the shading factor. It increases rapidly with $c$, where its value approaches unlty for $c=60^{\circ}$, as shown in the tigure.

\section{CONCLUSI ONS}

The shading effect of a south building block on the aperture of a solar device in the north latitudes $\left(0-64^{\circ}\right)$ is theoretically investigated. A mathematical model to calculate the shading Eactor, which is defined by the ratio of actual total solar radiation on the aperture surface to that vithout shading, as a Eunction of system geometrical parameters ls presented. The hourly, daily and annual average values of shading factor, which can be easily calculated by thls model, may be of great help when a site ls to be tested for the installation of a solar device in large citieg. Results uhich are given in graphical form can be used in a gulck and accurate egtiration of shading factor for any 
Mansouza Engineering Journal(HEJ) vol.14, No.1, June 1989 M 102

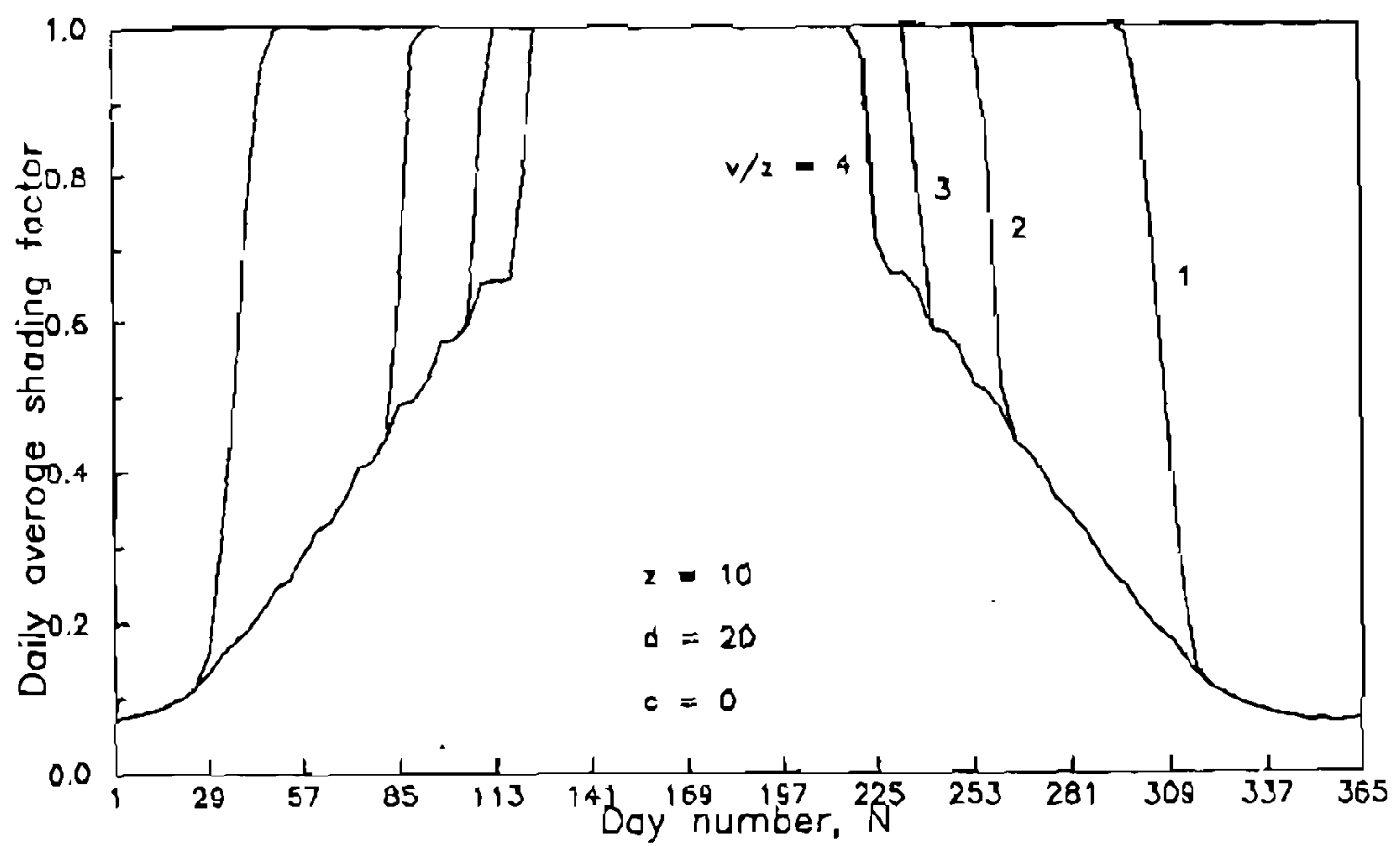

Fig. 7. Doilv averoce shaci. "-ztor for different building heights.

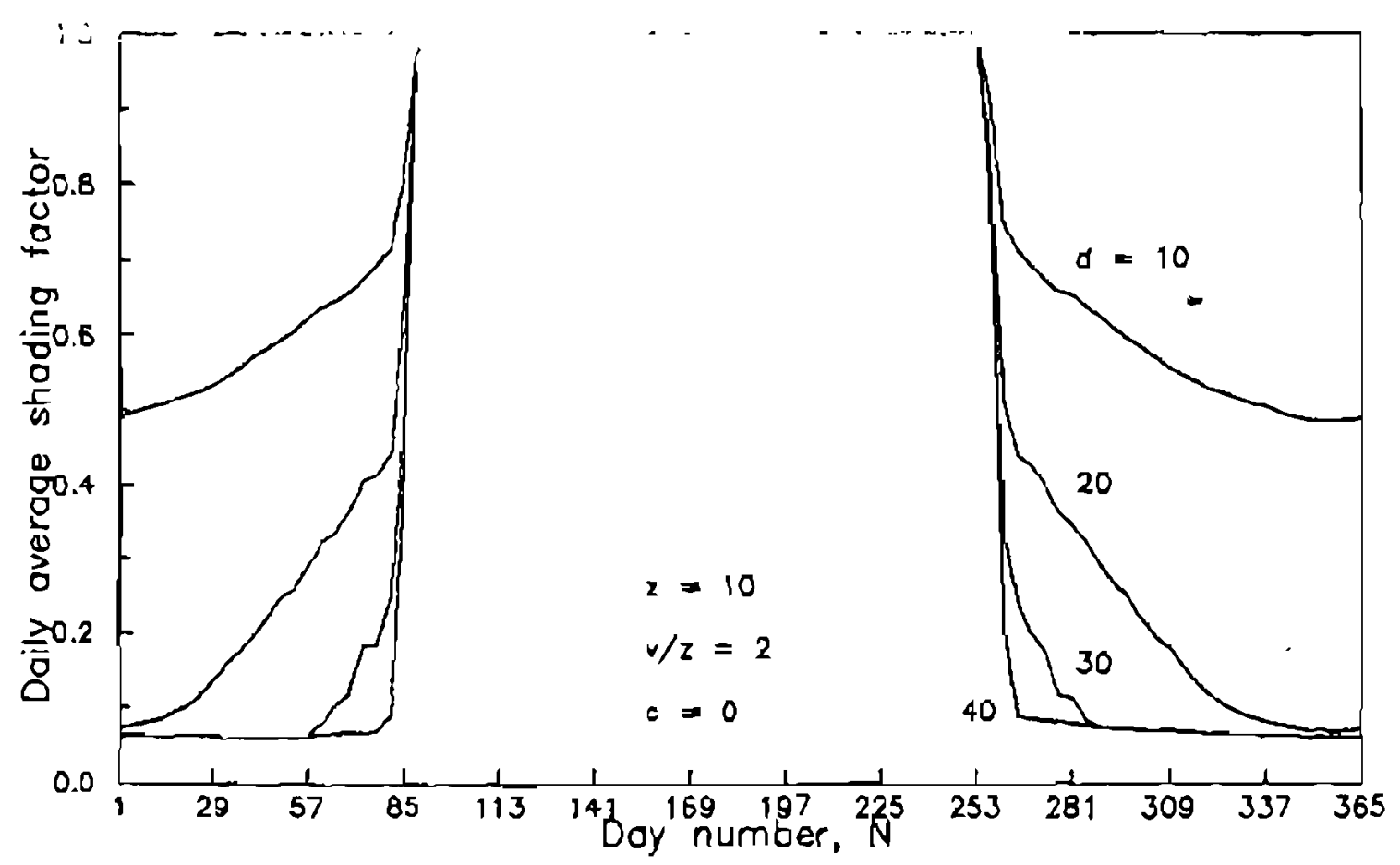

Fig. 8. Doily overoge shoding foctor for different building widths. 


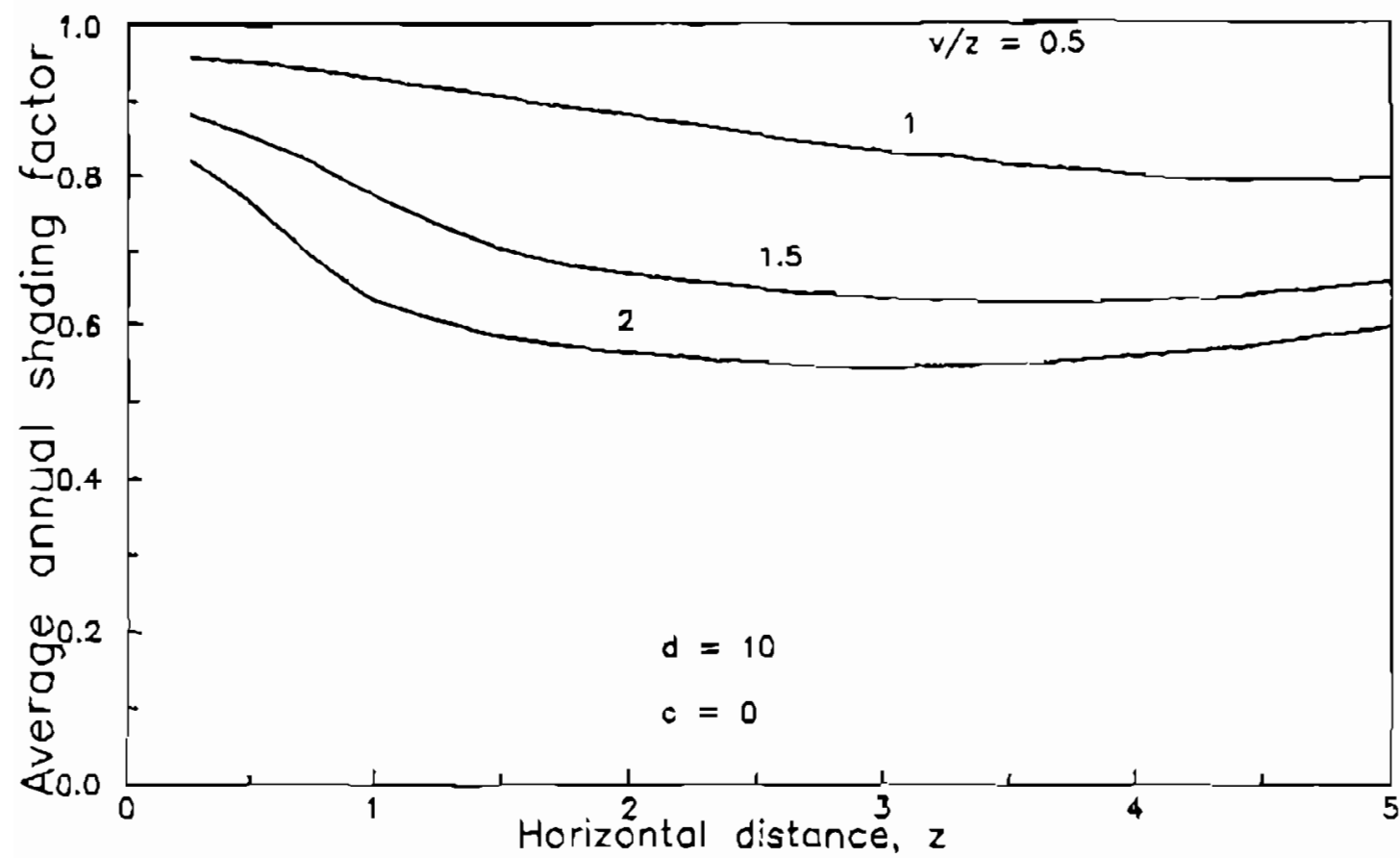

Fig. 9. Annual shading factor for a near southeren object.

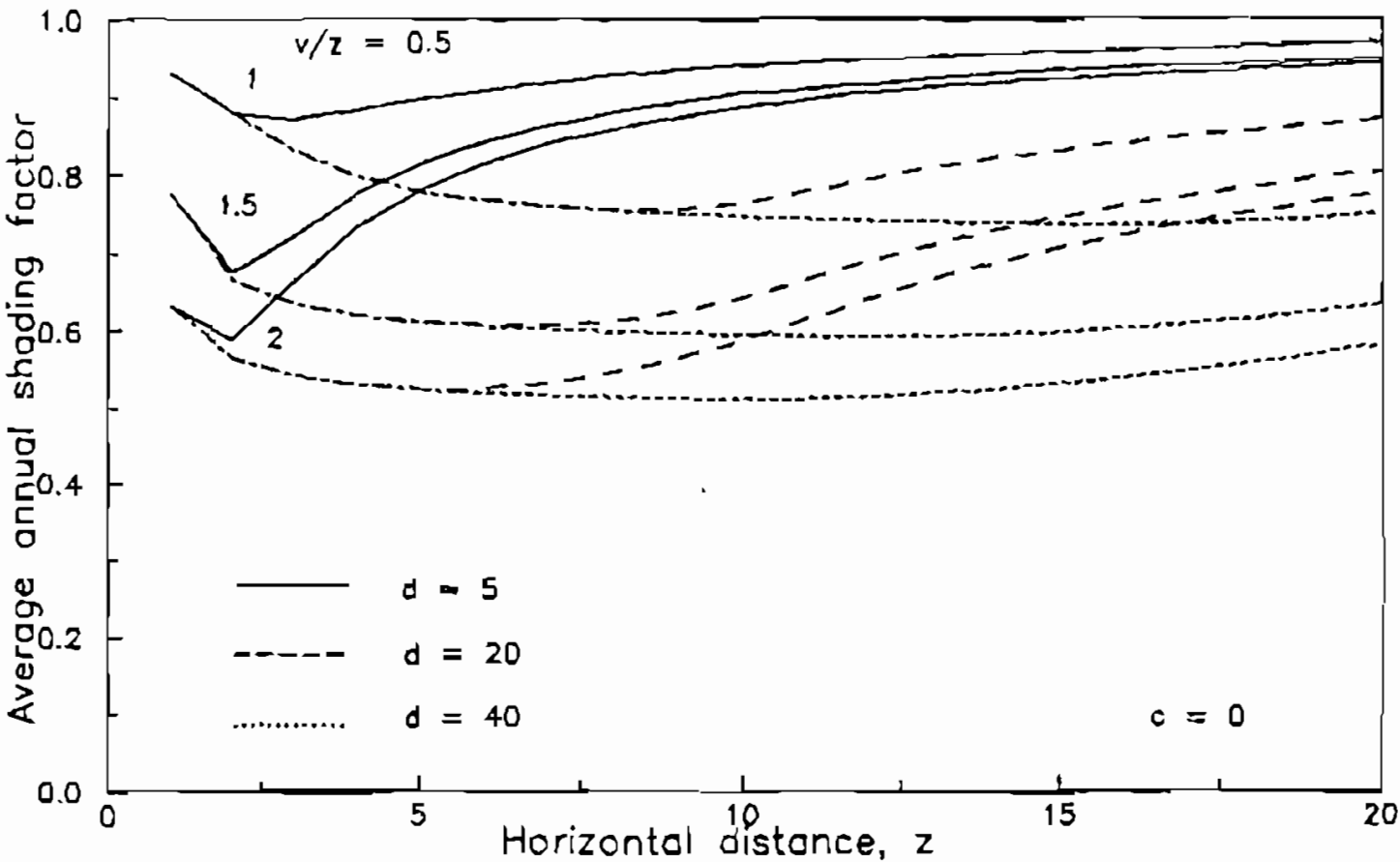

Fig. 10. Average annual shoding factar vs. horizontal distance far different values of building heights and widhs. 


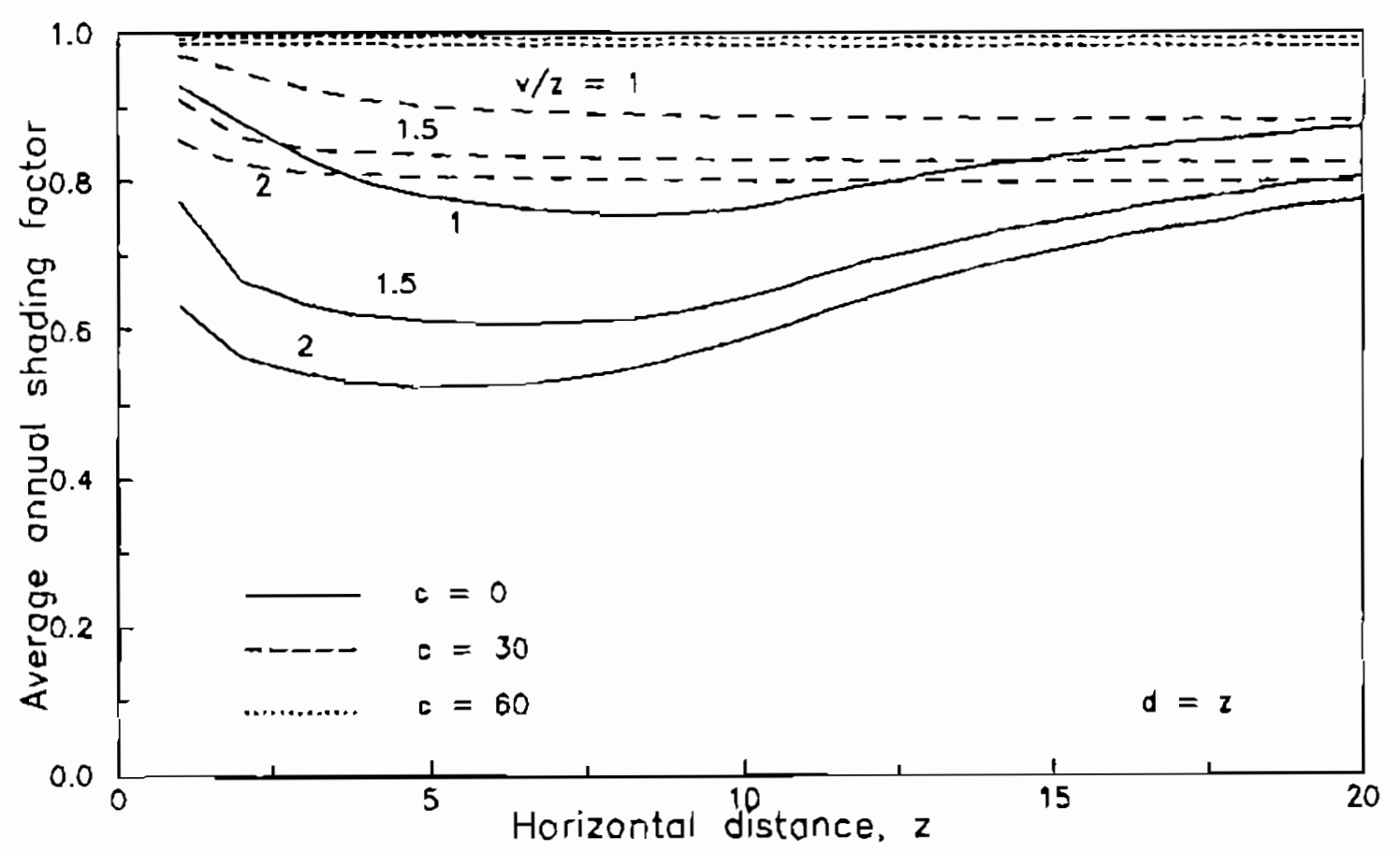

Fig. 11. Average annual shading factor vs. horizontal distance for different volues of angle $c_{\text {, }}$ and building heights. 
system geometry, since all parameters are dimensionless.

\section{NOHENCLATUPE}

A. Ratio of the shaded area to that of the aperture

a Solar arlmuth angle, rad. (ulth normal slgn convention).

c Angular deviation of the building from south direction, rad. Ratio of building vidth to that of aperture in E-H direction Aperture aspect ratio Diffuse radiation factor

$H_{\text {bn }}$ Beam solar zadiation intensity at normal lncidence, $\mathrm{W} / \mathrm{m}^{2}$

$\mathrm{H}_{d a}$ Dlffuse solar radiation intensity on aperture surface, $\mathrm{W} / \mathrm{m}^{2}$

L Aperture height, $m$

1 Length of shade in the aperture height, $\pi$

$N$ Number of days from January first

$v$ Building height, m

$v$ Ratio of building height to that of aperture

w Aperture vidth, m

2 Horlzontal distance betueen building and aperture, m $z$ Ratio between the horizontal distance and aperture height

a Solar altitude angle, rad.

a Aperture tilt angle, rad.

$y$ Aperture surface zimuth angle, rad.

$\theta$ Incident angle of beam radiation on apezture surface, rad

$\lambda$ Profile angle, rad.

\section{RETEPEICES}

1. R. E. Jones Jr, "Effects of overhang shading of vindous havlng arbitrary azimuth", Solar Energy, Vol. 24, 305 (1980).

2. R. F. Yanda and R. E. Jones Jr, "shading effects of finite vidth overhang on windows facing touard the equator", solar Energy, Vol. 30, 171 (1983).

3. G. S. Barozzi and R. Grossa," Shading effect of eggcrate devices on vertical uindous of arbitrary orlentation", solar Energy, Vol. 39, 329 (1987).

4. R. E. Jones $J r$ and $J$, F. Burkhart,"Shading effect of collector rous tilted toward the equator", Solar Energy, Vol.26,563(1981)

5. J. Feldman, S. Slnger and A. Eraunstein,"Solar cell interconnections and the shacou problem", Solar Energy,vol. 26, $119(1981)$

6. R. Budin and L. Budin, "A mathematical model for shading calculations", Solar Energy, Vol. 29, 339 (1982).

7. ASHRAE Handbook of Fundamentals, 1981. 